\title{
Three Dimensional Shear Stress Along Bonded Interface between Fiber Reinforced Plasticplate and Concrete
}

\author{
X.H. Chang \\ Yellow River Conservancy Commission of the Ministry of Water Resources \\ Zhengzhou , P.R. China
}

\author{
H.H. Xi \\ Yellow River Conservancy Commission of the Ministry of \\ Water Resources \\ Zhengzhou, P.R. China \\ L. Zhang \\ Yellow River Institute of Hydraulic Research \\ YRCC \\ Zhengzhou, P.R. China
}

\begin{abstract}
The bonded interface between fiber reinforced plastic (FRP)plate and the concrete members is a key part while reinforcing the concrete structures with FRP plates. Under some external loading conditions, this interface was oftenin the direct shear action. Therefore, accurate measurement and analysis of interfacial shear stress distribution was the precondition of FRP plate reinforced concrete structural design. The ASTM D905 shear specimens were improved, the shear test of the bonded FRP-concrete interface was simulated by using three-dimensional finite element method, and the shear stress distribution was obtained. The stress distribution characteristics on the interfacewas discussed, the stress concentration factor (SCF) for the characterization of specimen actual shear strength was well obtained.The resultswill play an important role on the study the interfacial fracture by thestress concentration in gaps.
\end{abstract}

Keywords-FRP ; concrete ; shear ; stress concentration factor; structural reinforcement; three-dimensional

\section{INTRODUCTION}

The bonding surface between fiber reinforced plastic (FRP)plate and concrete is the key part of FRP plate reinforced concrete structure. The failure of reinforced structure was often caused by tiny cracks of bonding surface, and then developed into the larger cracks, eventually led to damage as a whole structure. Interfacial bonding strength was divided into shear bond strength (parallel to the bonding interface) and tensile bond strength (perpendicular to the interface), and the bonding interface was often in a shear stress state under some external loading conditions. Therefore, accurate measurement and analysis of adhesive interfacial shear stress distribution is the precondition of FRP plate reinforced concrete structural design.

\author{
Y. Yang \\ Yellow River Institute of Hydraulic Research, YRCC \\ Zhengzhou, P.R. China \\ J. Zheng \\ Yellow River Institute of Hydraulic Research \\ YRCC \\ Zhengzhou, P.R. China
}

On shear bond strength of reinforced concrete structure by FRP plate, some scholars [1-4] conducted a large numbers of experimental analysis and theoretical research, however, owing to the lack of unified measurement shear bond strength of the bonding interface standards or specifications, the test method adopted was not same, mainly include single, double shear, block shear test, three point bending beam test, fourpoint bending beam test, five-point bending beam test and torsion test. Among them, the first three tests mainly aimed at small specimens, the last four methods were mainly used for large specimens. A large numbers of research and tests showed that $[5,6]$ : the shear strength of specimens measured by beam shear method was generally less than the block shear test, therefore, in terms of engineering safety, the block shear test method was more inclined to adopt. The ASTM D905 was used to measure the bonded shear strength of lumber by the American Society for Testing Material [7]. It was important to note that shear strength was the ultimate limit pressure load divided by the corresponding shear failure area, which was the average shear strength, it met the assumption of uniform distribution on the interface shear stress. But in fact, the stress along bonding interface was not equally distributed. As early as 1955, Yavorsky and Cunningham [8] studied the bonding interfacial strain distribution of ASTM D905 specimens by strain indicating paint, the results showed that the interfacial shear stress distribution was not uniform, and was not a pure shear stress, which was owing to stress concentration and tensile stress existed in the specimens notch. Therefore, the methods underestimated the real shear strength of bonding interface.

Zhang [8] carried out numerical simulation of shear test of the FRP-concrete bonded interface by adopting the bi- 
dimensional finite element method. But it was much difference between the two-dimensional FEM calculation and the threedimensional FEM calculation. Therefore, it was urgent to study the influence of the stress concentration of the block shear specimen to the shear strength of the bonded FRPconcrete interface by three-dimensional FEM, interfacial shear stress distribution will be obtained, and it is very useful for designing the shear-resisting bonding strength test as well as characterizing the FRP-strengthened concrete bonded interface.

\section{Model TeSt AND Numerical Simulation}

With reference to ASTM D905 shear test method, shear specimens were improved, the length of the concrete block was $50.8 \mathrm{~cm}$, the width was $19.05 \mathrm{~cm}$, the height was 44.45 $\mathrm{cm}$, and the thickness of the FRP plate can be adjusted freely. In order to prevent specimen upsetting, the surface of loading device was roughly same as loading surface of the concrete, the gap of specimen was limited by lateral displacement and vertical displacement, the bottom gap of specimen was under vertical and horizontal constraint. The uniform vertical displacement was applied to simulate test load, as shown in fig. 1 .



(a)shear specimens

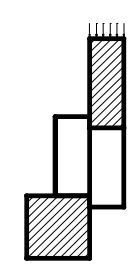

(b)load conditions
FIGURE I. IMPROVED SHEAR STRENGTH TEST

On the assumption that shear stress of FRP and concrete interface was under the premise of uniform distribution, interfacial shear strength expression was:

$$
\tau_{f-c}=P_{u} / A(1)
$$

where, $\tau_{f-c}$ was shear strength of FRP and concrete, $P_{u}$ was ultimate load, which was external load imposed when the shear specimen damage, $A$ was the area of FRP-concrete bonded interface.

The displacement control method was applied on the specimen, limit load cannot be determined in advance, so the interface shear strength was assumed as $\tau_{f-c}^{\prime}$, bonded interface damage area was assumed as $A$, then the ultimate applied load was:

$$
P_{u}=\tau_{f-c}^{\prime} \cdot A(2)
$$

A certain displacement load was imposed on the specimen, the actual load applied on the specimen can be obtained through the finite element analysis, which was resultant force loading on the surface, recorded as $\Sigma P$, the ratio of applied external forces and limit external forces was $\phi$

$$
\phi=\Sigma P / P_{u}=\Sigma P / \tau_{f-c} \cdot A(3)
$$

Stress concentration due to gaps would be likely to result in uneven stress distribution of the bonded interface, the stress of the gaps will be far greater than the average shear stress calculated by eqn (1), and the stress concentration factor (SCF) was adopted to characterize the relationship between them, which was as follows:

$$
S C F=\tau_{\max } / \tau_{f-c}^{\prime}
$$

where, $\tau_{\max }$ was the maximum shearing stress on the bonding interface, while the interface shear stress was equal to ultimate shear stress. The stress distribution of FRP-concrete bonded interface by finite element analysis, was not the corresponding stress when it came to ultimate shear strength of interface, but with the scaling factor adjustment, the real SCF value can be obtained, which was

$$
S C F=\frac{\tau_{\max }}{\tau_{f-c}^{\prime}}=\frac{\tau_{i \max } / \phi}{\tau_{f-c}^{\prime}}=\frac{\tau_{i \max } \cdot A}{\Sigma P}
$$

where, $\tau_{i \max }$ was the maximum stress along FRP and concrete bonding interface calculated by finite element method under certain displacement. From eqn 5, it can be learned that SCF was not affected by shear strength of the FRP-concrete bonded interface, SCF was a fixed value for the determination of some materials. Therefore, as for SCF, it was of great significance for the characterization of specimen actual shear strength.

\section{A. Material Parameter}

There were no consistent conclusions in documents about FRP plate and concrete material property values, and the material properties were not the same as for different types of FRP and concrete plate. Referred to previous data and documents [9-10], it was assumed that concrete was isotropic material, and the concrete compressive strength grade was C25. FRP plate was selected as the carbon fiber reinforced polymer (CFRP), glass fiber reinforced polymer (GFRP) and boron fiber reinforced polymer (BFRP). They were all orthotropic material, and satisfied the conditions of transverse isotropy. Referred to the calculation formula of the elastic constants and practical engineering value about CFRP, GFRP and BFRP in

\begin{tabular}{|c|c|c|c|c|c|c|c|c|c|}
\hline & $\begin{array}{c}E_{1} \\
/ G P \\
a \\
\end{array}$ & $\begin{array}{c}E_{2} \\
/ G P \\
a\end{array}$ & $\begin{array}{c}E_{3} \\
/ G P \\
a \\
\end{array}$ & $v_{12}$ & $v_{13}$ & $v_{23}$ & $\begin{array}{c}G_{12} \\
/ G P \\
a \\
\end{array}$ & $\begin{array}{c}G_{13} \\
/ G P \\
a \\
\end{array}$ & $\begin{array}{c}G_{23} \\
/ G P \\
a \\
\end{array}$ \\
\hline $\begin{array}{l}\text { Concr } \\
\text { ete }\end{array}$ & $\begin{array}{c}27.5 \\
79\end{array}$ & $\begin{array}{c}27.5 \\
79\end{array}$ & $\begin{array}{c}27.5 \\
79\end{array}$ & 0.2 & 0.2 & 0.2 & $\begin{array}{c}14.4 \\
96\end{array}$ & $\begin{array}{c}14.4 \\
96\end{array}$ & $\begin{array}{c}14.4 \\
96\end{array}$ \\
\hline BFRP & 204 & $\begin{array}{c}118 . \\
5\end{array}$ & $\begin{array}{c}118 . \\
5\end{array}$ & $\begin{array}{c}0.2 \\
7\end{array}$ & $\begin{array}{c}0.2 \\
7\end{array}$ & $\begin{array}{c}0.3 \\
2\end{array}$ & 5.59 & 5.59 & $\begin{array}{c}78.3 \\
88\end{array}$ \\
\hline CFRP & 181 & $\begin{array}{c}100 . \\
3\end{array}$ & $\begin{array}{c}100 . \\
3\end{array}$ & $\begin{array}{c}0.3 \\
2\end{array}$ & $\begin{array}{c}0.3 \\
2\end{array}$ & $\begin{array}{c}0.4 \\
8\end{array}$ & 7.17 & 7.17 & $\begin{array}{c}74.0 \\
21\end{array}$ \\
\hline GFRP & 38.6 & $\begin{array}{c}18.2 \\
7\end{array}$ & $\begin{array}{c}18.2 \\
7\end{array}$ & $\begin{array}{c}0.2 \\
8\end{array}$ & $\begin{array}{c}0.2 \\
8\end{array}$ & $\begin{array}{c}0.3 \\
4\end{array}$ & 4.14 & 4.14 & $\begin{array}{c}12.2 \\
5\end{array}$ \\
\hline
\end{tabular}
the literature [9], the material properties of FRP sheet and concrete were as shown in table 1, the 1-st direction was the main direction of FRP sheet.

TABLE I. MATERIAL PROPERTY PARAMETER 
Note: $\mathrm{E}_{1}, \mathrm{E}_{2}, \mathrm{E}_{3}-$ Elasticity Modulus; $v_{12}, v_{13}, v_{23}$ - Poisson's ratio; $\mathrm{G}_{12}, \mathrm{G}_{13}, \mathrm{G}_{23}$ - Shear Modulus

For FRP sheets, the elastic constants satisfied eqn (6)

$$
\begin{aligned}
& E_{2}=E_{3}, \quad G_{12}=G_{13}, \quad v_{23}=v_{32}, \quad v_{12}=v_{13}, \quad v_{21}=v_{31} \\
& G_{23}=\frac{E_{2}}{2\left(1+v_{23}\right)}
\end{aligned}
$$

\section{THE FINITE ELEMENT MODEL}

Three-dimensional finite element model was established by finite element software ADINA, it was refined locally for the grid of bonding interface and the load surface, as shown in fig. 2 . In addition to the grid locally refinement, there were 5 $\mathrm{cm}$ and $10 \mathrm{~cm}$ grid mesh division respectively in the direction of the specimen thickness (X direction), and $2 \mathrm{~cm}$ and $4 \mathrm{~cm}$ grid mesh division respectively in the specimen length direction ( $\mathrm{Z}$ direction) and the width direction ( $\mathrm{Y}$ direction).

Due to space limitations, there were only listed two kinds of BFRP sheets grid model, the first case was that the thickness direction ( $\mathrm{X}$ direction) was $5 \mathrm{~cm}$, the length direction ( $\mathrm{Z}$ direction) and the width direction ( $\mathrm{Y}$ direction) were both $2 \mathrm{~cm}$, as shown in fig. 2 (a); the second case was that the thickness direction (X direction) was $10 \mathrm{~cm}$, the length direction ( $\mathrm{Z}$ direction) and the width direction ( $\mathrm{Y}$ direction) were both $4 \mathrm{~cm}$, as shown in fig. 2 (b).

The left part was the FRP plate in the model, the right part was concrete, whose thickness was same, their material 1 direction was $\mathrm{Z}$ direction. 27-nodes three dimensional element was used for FRP plate and concrete parts, adhesive contact element was set for bonding between FRP plate and concrete surface. FRP sheet was constrained in vertical direction at the bottom, was constrained in lateral horizontal direction in the upper, and the concrete was constrained in lateral horizontal direction at the bottom. In order to simulate the actual load, displacement of $0.01 \mathrm{~mm} / \mathrm{s}$ uniform load was applied on the right side of the specimen, as shown in fig. 2 .

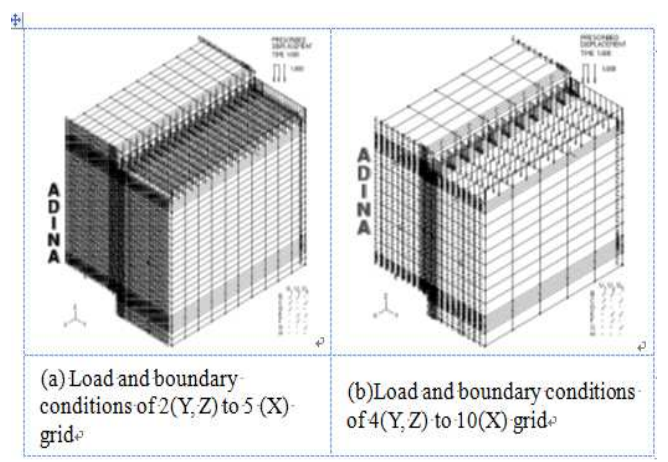

FIGURE II. FINITE ELEMENT MODEL OF IMPROVED ASTM D905 SHEAR TEST

The shear stress distribution of BFRP and concrete bonded interface was obtained as shown in fig. 3 under different mesh density. The shear stress distribution at different depth of BFRP sheets and concrete bonded interface were obtained as shown in fig. 4.

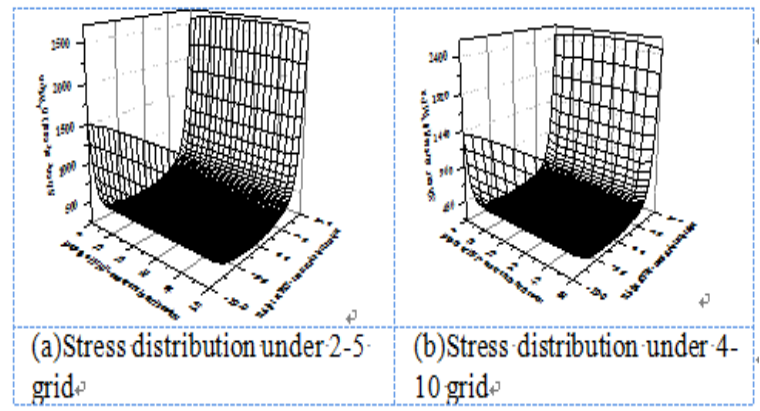

FIGURE III. SHEAR STRESS DISTRIBUTION OF BFRP AND CONCRETE INTERFACE



FIGURE IV. SHEAR STRESS DISTRIBUTION AT DIFFERENT DEPTH OF BFRP -CONCRETE INTERFACE

Note: The first number represented the length and width direction of the mesh size, the second number represented the thickness direction of the mesh size, the third number represented the depth of the interface.

From fig. 3 and fig. 4, it can be came to the following results:

(1) The shear stress distribution of FRP and concrete interface were roughly same with different mesh density.

(2) It was roughly same that the calculation of shear stress distribution along FRP and concrete interface in different depth under different mesh density, this showed that the stress along the interface of FRP and concrete changing with depth.

(3) It was very close that calculation results between threedimensional and two-dimensional FEA model for different depth of the interface shear stress, thus it can take simplified calculation by using the two-dimensional model in the future.

FRP and concrete interface SCF calculation results through the $3 \mathrm{~d}$ models and $2 \mathrm{~d}$ model under four different grid density are compared, which as shown in table 2 to table 4 .

\begin{tabular}{|c|c|c|c|c|c|c|}
\hline Mesh density & $2-5$ & $2-10$ & $4-5$ & $4-10$ & $\begin{array}{l}\text { Plane } \\
\text { stress }\end{array}$ & $\begin{array}{l}\text { Plane } \\
\text { strain }\end{array}$ \\
\hline$S C F$ & 4.276 & $\begin{array}{l}4.27 \\
6\end{array}$ & $\begin{array}{l}4.27 \\
9\end{array}$ & $\begin{array}{l}4.27 \\
9\end{array}$ & 4.407 & 4.276 \\
\hline $\begin{array}{c}\text { solving equation } \\
\text { number }\end{array}$ & $\begin{array}{l}14511 \\
2\end{array}$ & $\begin{array}{l}7373 \\
2\end{array}$ & $\begin{array}{l}616 \\
72\end{array}$ & $\begin{array}{l}3133 \\
2\end{array}$ & 4745 & 4745 \\
\hline $\begin{array}{c}\text { Solving time } \\
\text { (s) }\end{array}$ & 178.1 & $\begin{array}{l}30.4 \\
5\end{array}$ & $\begin{array}{l}40.9 \\
4\end{array}$ & 8.09 & 0.13 & 0.15 \\
\hline $\begin{array}{c}\text { RAM usage } \\
(\mathrm{mb})\end{array}$ & 1262.1 & $\begin{array}{l}425 \\
7\end{array}$ & $\begin{array}{l}422 . \\
8\end{array}$ & $\begin{array}{l}149 . \\
7\end{array}$ & 4 & 4 \\
\hline
\end{tabular}

TABLE II. SCF CALCULATION OF BFRP-CONCRETE BONDED INTERFACE 
TABLE III. SCFCALCULATION OF CFRP-CONCRETE BONDED INTERFACE

\begin{tabular}{|c|c|c|c|c|c|c|}
\hline Mesh density & $2-5$ & $2-10$ & $4-5$ & $4-10$ & $\begin{array}{l}\text { Plane } \\
\text { stress }\end{array}$ & $\begin{array}{l}\text { Plane } \\
\text { strain }\end{array}$ \\
\hline$S C F$ & 4.402 & $\begin{array}{l}4.40 \\
2\end{array}$ & $\begin{array}{l}4.4 \\
06\end{array}$ & $\begin{array}{l}4.40 \\
6\end{array}$ & 5.010 & 4.403 \\
\hline $\begin{array}{c}\text { solving } \\
\text { equation } \\
\text { number }\end{array}$ & $\begin{array}{l}1451 \\
12\end{array}$ & $\begin{array}{l}737 \\
32\end{array}$ & $\begin{array}{l}616 \\
72\end{array}$ & $\begin{array}{l}313 \\
32\end{array}$ & 4745 & 4745 \\
\hline $\begin{array}{c}\text { Solving time } \\
(s)\end{array}$ & $\begin{array}{l}177.5 \\
8\end{array}$ & $\begin{array}{l}30.9 \\
3\end{array}$ & $\begin{array}{l}40 . \\
6\end{array}$ & 7.96 & 0.12 & 0.13 \\
\hline $\begin{array}{c}\text { RAM usage } \\
(\mathrm{mb})\end{array}$ & $\begin{array}{l}1262 . \\
1\end{array}$ & $\begin{array}{l}425 . \\
7\end{array}$ & $\begin{array}{l}422 \\
.8\end{array}$ & $\begin{array}{l}149 . \\
7\end{array}$ & 4 & 4 \\
\hline
\end{tabular}

TABLE IV. SCFCALCULATION OF GFRP-CONCRETE BONDED INTERFACE

\begin{tabular}{|c|c|c|c|c|c|c|}
\hline Mesh density & $2-5$ & $2-10$ & $4-5$ & $4-10$ & $\begin{array}{l}\text { Plane } \\
\text { stress }\end{array}$ & $\begin{array}{l}\text { Plane } \\
\text { strain }\end{array}$ \\
\hline$S C F$ & 6.477 & $\begin{array}{l}6.47 \\
7\end{array}$ & $\begin{array}{l}6.4 \\
80\end{array}$ & $\begin{array}{l}6.48 \\
0\end{array}$ & 6.939 & 6.477 \\
\hline $\begin{array}{l}\text { solving } \\
\text { equation } \\
\text { number }\end{array}$ & 14511 & $\begin{array}{l}737 \\
3\end{array}$ & $\begin{array}{l}616 \\
7\end{array}$ & $\begin{array}{l}3133 \\
2\end{array}$ & 4745 & 4745 \\
\hline $\begin{array}{l}\text { Solving } \\
\text { (s) }\end{array}$ & $\begin{array}{l}185.4 \\
9\end{array}$ & $\begin{array}{l}30.1 \\
7\end{array}$ & $\begin{array}{l}42 . \\
01\end{array}$ & 8.02 & 0.12 & 0.12 \\
\hline$\underset{(M b)}{R A M}$ usage & $\begin{array}{l}1262 . \\
1\end{array}$ & $\begin{array}{l}425 \\
7\end{array}$ & $\begin{array}{l}422 \\
.8\end{array}$ & $\begin{array}{l}149 . \\
7\end{array}$ & 4 & 4 \\
\hline
\end{tabular}

It can be obtained from table 2 to table 4 as follows:

(1) It was more economic and simple three-dimensional finite element mesh grid that the transverse mesh density was $2 \mathrm{~cm}$, and the longitudinal direction and the depth mesh density were $10 \mathrm{~cm}$.

(2) The grid density slightly affected the results of the SCF, but the mesh density in the thickness direction had less effect on the calculation results for the improved D905 specimens, even can be ignored.

\section{CONCLUSION}

Based on the shear bond strength of FRP and concrete bonded interface, ASTM standard D905 shear specimens had been improved, bonded interface shear test of FRP plate reinforced concrete member was simulated by using threedimensional finite element method, the main conclusions were as follows:

(1) Due to different material properties of concrete and FRP and the discontinuity of geometrical shapes at the notches, obvious stress concentration appeared on the upper and bottom ends of the FRP-concrete interface, which indicated the initial fracture resulting in the shear failure on the FRP-concrete bonded interface.

(2) Shear stress distribution and SCF calculation by threedimensional finite element method can be simplified as a twodimensional plane strain problem for analysis.

\section{ACKNOWLEDGEMENTS}

This work was financially supported by the National Natural Science Foundation of China (51209102), and fundamental research funds for the central nonprofit research institutions (HKY-JBYW-2013-04).

\section{REFERENCES}

[1] Chajes, M.J., et al., Bond and force transfer of composite material plates bonded to concrete. ACI Structural Journal,93(2): pp. 208-217, 1996.

[2] Chen, J.F. and J.G. Teng, Anchorage strength models for FRP and steel plates bonded to concrete. Journal of Structural Engineering, 127(7), pp. 784-791, 2001.

[3] Taljsten, B., Defining anchor lengths of steel and CFRP plates bonded to concrete. International Journal of Adhesion and Adhesives,17(4), pp. 319-327, 1997.

[4] Bizindavyi, L. and K.W. Neale, Transfer lengths and bond strengths for composites bonded to concrete. Journal of Composites for Construction, 3(4), pp. 153-160, 1999.

[5] Longworth, J., Longitudinal shear strength of timber beams. Forest Products Journal, 27(8), pp. 19-23, 1997.

[6] Radcliffe, B.M. and S.K. Suddarth, The notched beam shear test for wood. Forest Products Journal, 5(2), pp. 131-135, 1955.

[7] ASTM Standard D905, Standard Test Method for Strength Properties of Adhesive Bonds in Shear by Compression Loading,ASTM International, West Conshohocken, PA, 2013, DOI: 10.1520/D0905, www.astm.org, 2013.

[8] Zhang L, Wang J, Zhou K, et al. Two-dimensional Shear Stress on Bonding Interface of FRP Plate Reinforced Hydraulic Concrete. Applied Mechanics and Materials,477-478, pp. 850-857, 2014.

[9] Saadatmanesh, H. and A.M. Malek, Design guidelines for flexural strengthening of RC beams with FRP plates. Journal of Composites for Construction, 2(4), pp. 158-164, 1998.

[10] Barbero, E.J., Introduction to composite materials design. Taylor and Francis:Philadelphia, PA, 1999. 